\title{
Estimating ventilation rates in a window-aired room using Kalman filtering and considering uncertain measurements of occupancy and $\mathrm{CO}_{2}$ concentration
}

\author{
Rogério Duarte $^{1}$, M. Glória Gomes ${ }^{2}$, and A. Moret Rodrigues ${ }^{2}$ \\ ${ }^{1}$ CINEA, DEM, Escola Superior de Tecnologia de Setúbal, Instituto Politécnico de Setúbal, Campus do IPS, Estefanilha, \\ 2914-761 Setúbal, Portugal \\ ${ }^{2}$ CEris, ICIST, DECivil, Instituto Superior Técnico, Universidade de Lisboa, Av. Rovisco Pais 1, 1049-001 Lisbon, Portugal \\ Correspondence to: Rogério Duarte \\ (rogerio.duarte@estsetubal.ips.pt)
}

\begin{abstract}
This paper describes a method for estimating ventilation rates in a window-aired room considering "in-use" conditions and uncertainty in occupancy $\left(\mathrm{CO}_{2}\right.$ release $)$ and in measurements of indoor air $\mathrm{CO}_{2}$ concentration. Estimates are drawn from indoor air mass conservation principles and an Extended Kalman Filter, serving as state observer. The modelling procedure is described and tested against synthetic time series generated from pseudorandom values of occupancy and ventilation rate. Additionally, data collected from a case study (a window-aired classroom) is used to illustrate how the procedure is applied and its practical interest. Test results confirm the state observer's tracking capability and confirm its ability to reconstruct ventilation rates in the presence of sudden changes caused by window opening/ closing and intermittent occupancy. Results for the case study highlight the benefits to designers and ultimately to occupants, derived from knowledge of ventilation rates in window-aired rooms.
\end{abstract}

Keywords. Natural ventilation; window airing; manual opening of windows; Extended Kalman Filter; state observer; school classroom (jobname:paper02 $\mathrm{rdF} 02$.tex)

\section{Highlights}

- A state space model that considers uncertainty in occupancy $\left(\mathrm{CO}_{2}\right.$ release $)$ and in measurements of indoor $\mathrm{CO}_{2}$ concentration is derived.

- A state observer based on this model and Kalman filtering is successful in estimating "quasi-instantaneous" ventilation rates in a window-aired room.
- The link between the uncertainty in estimates of ventilation rate and the uncertainty in occupancy $\left(\mathrm{CO}_{2}\right.$ release $)$ is discussed in detail.

- Results for an existing classroom demonstrate the practical interest of knowing ventilation rates in windowaired rooms.

\section{Introduction}

Natural ventilation with window airing is the traditional and still the most common room ventilation solution. It relies on manual opening/ closing of windows and ventilation is, therefore, subject to direct control by occupants. When window-aired rooms are heated, self-regulating equipments are generally used, resulting in very simple control solutions. This simplicity has obvious merits, but comes with a consequence: records of indoor conditions (e.g., records of air temperature and $\mathrm{CO}_{2}$ concentration) are not needed and objective evaluations of the indoor environment are hardly ever made. The lack of objective data is particularly regrettable when studying window-aired rooms because indoor conditions are free-running and without records designers and building managers have no means to assess if and when ventilation design specifications are being met. Feedback from occupants can be used, however, it is difficult to express subjective opinions on ventilation rates and occupants' assessments are typically biased towards their interest in keeping comfortable indoor air temperatures (Griffiths and Eftekhari, 2008). As a consequence, ventilation rates in window-aired rooms are often inappropriate (Santamouris et al., 2008; Pegas et al., 2011; Almeida and Fre- 


\begin{tabular}{|c|c|c|c|c|}
\hline \multicolumn{5}{|l|}{ Nomenclature } \\
\hline & (Bold is used to denote vector-valued variables) & $\boldsymbol{x}$ & : & state vector \\
\hline & & $y$ & : & noise-free output vector \\
\hline $\boldsymbol{A}$ & : vector-valued gradient & $z$ & : & noise-corrupted output vector \\
\hline$c=C-C_{\text {ext }}$ & : relative concentration of tracer gas, $\mathrm{ppm}$ & $\Delta$ & : & time-step duration \\
\hline$C$ & : absolute concentration of tracer gas, $\mathrm{ppm}$ & $\varepsilon$ & : & residue \\
\hline$E(\cdot)$ & : expected value & $\nu$ & : & measurement white noise \\
\hline$f(\cdot)$ & : scalar-valued function & $\sigma$ & : & standard deviation \\
\hline $\boldsymbol{F}$ & : $\quad$ state matrix & $\sum$ & : & sum \\
\hline $\boldsymbol{H}$ & : $\quad$ output matrix & $\phi$ & : & state transition scalar \\
\hline $\boldsymbol{I}$ & : identity matrix & $\omega$ & : & process white noise (continuous scalar) \\
\hline $\boldsymbol{K}$ & : Kalman gain & $\{\cdot\}$ & : & time series or sequence \\
\hline$n$ & : $\quad$ air change rate, $\mathrm{s}^{-1}$ & & & \\
\hline$N$ & : number of persons & Superscripts & & \\
\hline $\mathcal{N}$ & : referring to Gaussian probability & $\hat{\imath}$ & : & estimate (predicted or updated) \\
\hline & distribution & $\tilde{\sim}$ & : & error (predicted or estimated) \\
\hline $\boldsymbol{P}$ & : $\quad$ error covariance (predicted or updated) & $\overline{-}$ & : & average \\
\hline$q$ & $\begin{array}{l}\text { volumetric flow rate per person, } \\
\mathrm{m}^{3} / \mathrm{s} / \text { person }\end{array}$ & $c$ & : & $\begin{array}{l}\text { referring to indoor tracer gas } \\
\text { concentration }\end{array}$ \\
\hline$Q$ & : volumetric flow rate, $\mathrm{m}^{3} / \mathrm{s}$ & $n$ & : & referring to ventilation rate \\
\hline$r$ & : $\quad$ process white noise (discrete scalar) & $S$ & : & referring to tracer gas release \\
\hline $\boldsymbol{R}$ & : process noise covariance & $T$ & : & transpose \\
\hline$s$ & $\begin{array}{l}\text { production rate of tracer gas per person, } \\
\mathrm{cm}^{3} / \mathrm{s} / \text { person }\end{array}$ & $\dagger$ & : & $\begin{array}{l}\text { noise-corrupted, measured or } \\
\text { synthetic variable }\end{array}$ \\
\hline$S$ & : $\quad$ production rate of tracer gas, $\mathrm{cm}^{3} / \mathrm{s}$ & Subscripts & & \\
\hline$S$ & : residual covariance & 0 & : & initial condition \\
\hline$t$ & : time, $\mathrm{s}$ & ext & : & referring to outdoor (or atmospheric) \\
\hline$T$ & : temperature (air), ${ }^{\circ} \mathrm{C}$ & int & : & referring to indoor \\
\hline$V$ & : $\quad$ volume, $\mathrm{m}^{3}$ & $k$ & : & timestep \\
\hline $\boldsymbol{V}$ & : measurement noise covariance & meas & : & referring to measurement \\
\hline $\boldsymbol{W}(\cdot)$ & : Wiener process & proc & : & referring to process \\
\hline
\end{tabular}

itas, 2014; Pereira et al., 2014), with harmful consequences to occupants' health (Fraga et al., 2008; Bartlett et al., 2004; Rudnick and Milton, 2003) and lower productivity levels (Mendell and Heath, 2005; Wargocki and Wyon, 2007a,b; Bakó-Biró et al., 2012; Petersen et al., 2015).

Previous studies by Geelen et al. (2008) and Wargocki and da-Silva (2015) have shown how knowledge of indoor air $\mathrm{CO}_{2}$ concentration could be used to influence patterns of window airing and improve indoor air quality in classrooms. Because indoor air quality depends on how the room is used and how it is being ventilated, knowledge of ventilation rates considering "in-use" conditions is a topic of obvious interest. Ventilation studies from the 1980s lay out the generic procedure to determine transient airflows in occupied rooms using occupant-generated $\mathrm{CO}_{2}$ as tracer gas (Penman, 1980; Penman and Rashid, 1982; Smith, 1988); since then, different approaches to this topic were proposed (e.g., Markov and Melikov, 2014; Bartlett et al., 2004)), however, most approaches assume the $\mathrm{CO}_{2}$ injected in the room(s) is accurately known, even though this is hardly ever the case for "in-use" conditions; in fact, since the first studies by Penman (1980), it was recognised that the uncertainty in $\mathrm{CO}_{2}$ release was paramount to obtaining accurate estimates of ventilation rate.
This paper introduces a procedure for estimating ventilation rates in a window-aired room considering "in-use" conditions and contemplating the uncertainty in occupancy $\left(\mathrm{CO}_{2}\right.$ release) and in measurements of indoor air $\mathrm{CO}_{2}$ concentration. The procedure uses indoor mass conservation principles and an Extended Kalman Filter to develop a state observer capable of finding "quasi-instantaneous" estimates of ventilation rate mean and variance. A test to assess the state observer is presented and, to illustrate its practical interest, ventilation rates in an existing window-aired classroom are estimated.

The development of the state observer and details on the implementation of the Extended Kalman Filter are described in the following section.

\section{Development of the state observer}

For a window-aired room, ventilation rates can be estimated from the conservation equation of a tracer gas released in the room. In the traditional volumetric form this equation reads ${ }^{1}$ (see Sherman, 1990; Jones, 1994),

\footnotetext{
${ }^{1} \mathrm{~A}$ list with the meaning of the symbols used is presented at the beginning of the paper.
} 
$\frac{d C}{d t}=-n\left(C-C_{\mathrm{ext}}\right)+\frac{1}{V} S$,

with initial condition $C(t=0)=C_{0}$.

Different methods that start off from Equation (1) to determine ventilation rates in single zones are presented in standards EN ISO 12569 (2000) and ASTM E741-00 (2006) when $n$ and $S$ are constant. Unfortunately, for window-aired rooms and "in-use" conditions, both $n$ and $S$ vary with time, therefore, standards are of little use.

To solve Equation (1) with varying values of $n$ and $S$ a "quasi-instantaneous" approach is generally used. Time series of indoor tracer gas concentration and tracer gas release are divided into smaller parts of duration $\Delta$, and the regression, integral or averaging techniques described in Sherman (1990) are used. A literature review suggests the regression technique is probably the most common (Penman, 1980; Penman and Rashid, 1982; Smith, 1988; Bartlett et al., 2004; Okuyama, 1990); it consists in finding ${ }^{2}$ the air change rate $n$ that best fits the sequence of tracer gas concentration $\{C\}$, using a mean value for $S$ obtained from the sequence of tracer gas release $\{S\}$.

At first sight, use of the regression technique should pose no difficulty; yet, various researchers have reported problems with the selection of duration $\Delta$, given the presence of noise in time series of tracer gas concentration.

\subsection{Considering the uncertainty in tracer gas concen- tration}

As described by different authors (Okuyama and Onishi, 2012; Smith, 1988; Sherman, 1990), records of tracer gas concentration typically include high frequency noise. If the "quasi-instantaneous" approach described previously is used and intervals $\Delta$ are too small, estimates $n$ are influenced by this noise. On the other hand, if intervals $\Delta$ are too large, the "averaging" implied in the above-mentioned techniques becomes excessive, hindering the ability to track sudden changes in ventilation rates. The selection of $\Delta$ requires, therefore, a compromise between noise reduction and tracking capability (see Smith, 1988).

To reduce the effect of noise some researchers (Okuyama and Onishi, 2012; Smith, 1988) choose to prefilter time series $\{C\}$ prior to applying the regression technique. However, for window-aired rooms and especially when room occupancy is intermittent, careful consideration should be given to the choice of the filter cutoff frequency. Indeed, the stochastic nature of the drivers of natural ventilation (i.e., wind speed and direction, outdoor air temperature) combined with erratic patterns of window/ door opening, lead to sudden and often large changes in tracer gas concentration, not related to

\footnotetext{
${ }^{2}$ In the least squares sense and for each part of duration $\Delta$ of the original time series.
}

sensor's noise. Under these circumstances, choosing an inadequate cutoff frequency may end up filtering relevant information, compromising ventilation rate estimates.

To reduce the subjectivity implied in the choice of $\Delta$ or in the choice of low-pass filter characteristics, Brabec and Jílek (2007) - studying the concentration of radon in an unoccupied room-show how a Kalman Filter and mass conservation principles can be used to find air change rates from time series of tracer gas concentration and release. Indeed, the Kalman Filter has been successfully applied in many different fields, including navigation, image processing or finance, and provides a general method to estimate a signal in the presence of noise. According to Ljung (1987), the Kalman Filter provides optimal trade-off between tracking ability and noise sensitivity.

The use of a Kalman Filter combined with the conservation equation (1) requires that a distinction is made between noise-corrupted and noise-free values of tracer gas concentration and, traditionally, implies the assumption of an additional term in Equation (1) to account for process noise ${ }^{3}$.

Arranging Equation (1) to meet the requirements of Kalman filtering, the dynamics of tracer gas concentration in a single-zone ventilated with fresh air is described by,

$$
\left\{\begin{array}{l}
\frac{d c}{d t}=-n c+\frac{S}{V}+\omega^{c} \\
c^{\dagger}=c+\nu^{c}
\end{array}\right.
$$

where relative (not absolute) values of tracer gas concentration are used. Moreover,

- $c$ represents noise-free relative tracer gas concentration;

- $c^{\dagger}$ represents noise-corrupted values of $c$ (from actual sensor readings);

- $\omega^{c}$ represents process noise associated with $c$, and;

- $\nu^{c}$ represents measurement noise associated with $c$.

In the study by Brabec and Jílek (2007) CO was used as tracer gas and accurate amounts released in the room were available. However, in occupied rooms CO cannot be used, in fact, "exogenous" tracer gases are generally avoided when studying occupied rooms, especially for prolonged exposures. To study "in-use" conditions, metabolic $\mathrm{CO}_{2}$ exhaled by occupants is the preferred and most common choice for tracer gas (Penman, 1980; ASTM D6245-98, 2002); but, using a gas generated by occupants makes the rate of tracer gas release uncertain, because: the number of occupants varies, and accurate counting may not be possible; and the metabolism of occupants varies with age, sex, activity level, therefore, typically, only an estimate of the average rate of $\mathrm{CO}_{2}$ released per person is available.

\footnotetext{
${ }^{3}$ See Jimenéz and Madsen (2008) for a discussion on the physical meaning of process noise.
} 
Penman (1980); Smith (1988) conclude that the uncertainty in the rate of metabolic $\mathrm{CO}_{2}$ released can justify significant errors in estimates of ventilation rate; and, as Equation (2a) clearly shows, given that $c, n$ and $S$ are interlinked, modelling the dynamics of $\mathrm{CO}_{2}$ concentration with "in-use" conditions would benefit from adding the uncertainty in $S$.

\subsection{Considering the uncertainty in $\mathrm{CO}_{2}$ metabolic pro- duction}

Expressing the rate of metabolic $\mathrm{CO}_{2}$ production as

$S=N \bar{s}$,

shows there are two possible sources of uncertainty for $S$ : one in $N$, the number of persons in the room; and the other in $\bar{s}$, the average rate of metabolic $\mathrm{CO}_{2}$ production per person.

Determining the number of persons in a room can be a complex task. In this paper, time-series $\{N\}$ are assumed known with accuracy ${ }^{4}$. As regards the average rate of metabolic $\mathrm{CO}_{2}$ release per person, its uncertainty depends on the type of room studied. An important case for which the uncertainty in $\bar{s}$ is large is that of classrooms used intermittently by classes of different grades. For this case, sudden changes in $\bar{s}$ occur along the school day and, for heterogeneous classes, it is often difficult to decide on an average rate of $\mathrm{CO}_{2}$ released per student.

A way to model the uncertainty in $\bar{s}$-and therefore in $S$-is to admit that known values of $\mathrm{CO}_{2}$ release are noisecorrupted and, as before for indoor air $\mathrm{CO}_{2}$ concentration, make $S$ the noise-free unknown variable and $S^{\dagger}$ the noisecorrupted known measurements. This allows Equation (2) to be rearranged in matrix format as,

$$
\left\{\begin{array}{l}
{\left[\begin{array}{l}
\frac{d c}{d t} \\
\frac{d S}{d t}
\end{array}\right]=\left[\begin{array}{cc}
-n & \frac{1}{V} \\
0 & 0
\end{array}\right]\left[\begin{array}{l}
c \\
S
\end{array}\right]+\left[\begin{array}{c}
\omega^{c} \\
\omega^{S}
\end{array}\right]} \\
{\left[\begin{array}{l}
c^{\dagger} \\
S^{\dagger}
\end{array}\right]=\left[\begin{array}{ll}
1 & 0 \\
0 & 1
\end{array}\right]\left[\begin{array}{l}
c \\
S
\end{array}\right]+\left[\begin{array}{l}
\nu^{c} \\
\nu^{S}
\end{array}\right]}
\end{array}\right.
$$

with $\omega^{S}$ and $\nu^{S}$ process and measurement noise associated with the rate of metabolic $\mathrm{CO}_{2}$ release, and the equation for $d S / d t$ in (4a) stating that (pseudo) process noise is the only cause for changes in $S$.

Equation (4) provides a state space representation for the dynamics of tracer gas concentration in a room, with variables $c$ and $S$ unknown state variables and vectors $\boldsymbol{\omega}_{k}=$ $\left[\omega^{c}, \omega^{S}\right]^{T}$ and $\nu_{k}=\left[\nu^{c}, \nu^{S}\right]^{T}$ made up of independent normally distributed white noise components. Estimates of state variables may be obtained with a state observer using noisecorrupted values $c^{\dagger}$ and $S^{\dagger}$; but, if the objective is to obtain

\footnotetext{
${ }^{4}$ This assumption could result from the decision to move the uncertainty in $N$ to $\bar{s}$.
}

estimates of ventilation rate, it is necessary that $n$ is made a state variable too, and this is not the case in Equation (4).

\subsection{State space representation for an observer of $n$}

Before turning $n$ into a state variable (an unobservable one) it should be mentioned that just like $c$ and $S, n$ is time dependent, which makes the equation for $d c / d t$ in (4a) nonlinear. Finding estimates of instantaneous ventilation rates $n$ is, therefore, a problem of adaptive system identification requiring linearisation.

The Extended Kalman Filter provides a simple and efficient way to handle nonlinear problems such as the one described (Chui and Chen, 2009). Since this paper uses a discrete version of the Extended Kalman Filter, the state space model including $n$ as a state variable is presented below as a set of difference (instead of differential-algebraic) equations,

$$
\left\{\begin{array}{c}
{\left[\begin{array}{c}
c_{k+1} \\
S_{k+1} \\
n_{k+1}
\end{array}\right]=\left[\begin{array}{c}
f_{k}\left(c_{k}, S_{k}, n_{k}\right) \\
S_{k} \\
n_{k}
\end{array}\right]+\left[\begin{array}{c}
r_{k}^{c} \\
r_{k}^{S} \\
r_{k}^{n}
\end{array}\right]} \\
{\left[\begin{array}{c}
c_{k}^{\dagger} \\
S_{k}^{\dagger}
\end{array}\right]=\left[\begin{array}{lll}
1 & 0 & 0 \\
0 & 1 & 0
\end{array}\right]\left[\begin{array}{l}
c_{k} \\
S_{k} \\
n_{k}
\end{array}\right]+\left[\begin{array}{c}
\nu_{k}^{c} \\
\nu_{k}^{S}
\end{array}\right]}
\end{array}\right.
$$

with

$f_{k}\left(c_{k}, S_{k}, n_{k}\right)=e^{-n_{k} \Delta} c_{k}+\left(1-e^{-n_{k} \Delta}\right) \frac{S_{k}}{n_{k} V}$

highlighting the non-linearity in the difference equation for $c_{k+1}$ and

$\boldsymbol{r}_{k}=\left[\begin{array}{c}r_{k}^{c} \\ r_{k}^{S} \\ r_{k}^{n}\end{array}\right]=\left[\begin{array}{c}\int_{(k) \Delta}^{(k+1) \Delta} e^{-n_{k} \cdot[(k+1) \Delta-\tau]} \omega^{c}(\tau) d \tau \\ \\ \int_{(k) \Delta}^{(k+1) \Delta} \omega^{S}(\tau) d \tau \\ \int_{(k) \Delta}^{(k+1) \Delta} \omega^{n}(\tau) d \tau\end{array}\right]$

To obtain the expressions in (5a), first of all the equation $d n / d t=\omega^{n}$ was added to those in (4a), associating, as before for $S$, changes in $n$ to (pseudo) process noise $\omega^{n}$ (see Chui and Chen, 2009, p.114). Then, time series are divided into small intervals of duration $\Delta$ and, for each interval, zero-order hold is assumed, making values of $n_{k}$ and $S_{k}$ constant. Equations (5a) are then derived using the state transition scalar $\phi(t)=\exp \left(-n_{k} t\right)$. General details on how to obtain the difference equations in (5a) are provided in books covering discrete state model analysis (Reid, 1983; D'Souza, 1988). Concerning the vector of process noise $\boldsymbol{r}_{k}$, it is assumed that $d \boldsymbol{W}(\tau)=\boldsymbol{\omega}(\tau) d \tau$ with $W(\tau)$ a Wiener process, and, as a consequence, vector $\boldsymbol{r}_{k}$ is normally distributed 
white noise with zero mean and with a variance-covariance matrix $\boldsymbol{R}$-which is here denoted as $\boldsymbol{r}_{k} \sim \mathcal{N}(0, \boldsymbol{R})$ (for details see Madsen and Holst, 1995).

Finally, as regards equations $(5 \mathrm{~b})$, these are obtained directly from (4b) with $\nu_{k} \sim \mathcal{N}(0, \boldsymbol{V})$, and $\boldsymbol{V}$ the variancecovariance matrix for the measurement noise components.

To proceed to the description of the Extended Kalman Filter, Equation (5) is represented in compact form,

$\left\{\begin{array}{c}\boldsymbol{x}_{k+1}=\boldsymbol{F}_{k}\left(\boldsymbol{x}_{k}\right)+\boldsymbol{r}_{k} \\ \boldsymbol{z}_{k}=\boldsymbol{H} \boldsymbol{x}_{k}+\boldsymbol{\nu}_{k}\end{array}\right.$

with $\boldsymbol{x}_{k}$ the state vector and $\boldsymbol{z}_{k}$ the measurements vector (since the components of this vector are measured).

\subsection{Extended Kalman Filter}

The Kalman Filter consists of a procedure allowing the updating of an estimate of state vector $\boldsymbol{x}_{k}$ when a new observation of the measurements vector $\boldsymbol{z}_{k}$ becomes available. The procedure has two stages, called the predictor stage and the updating stage, and starts by postulating there is a best estimator ${ }^{5}$ for $\boldsymbol{x}_{k-1}$-denoted $\hat{\boldsymbol{x}}_{k-1}$-obtained from time series up to time $k-1$.

The predictor stage is concerned with forecasting $\boldsymbol{x}_{k}$ from time $k-1$, and the resulting estimator, $\hat{\boldsymbol{x}}_{k \mid k-1}$, is obtained observing how mean values of $\boldsymbol{x}_{k}$ propagate through time; that is, from Equation (8a) and recalling $\boldsymbol{r}_{k}$ is white noise with zero mean,

$\hat{\boldsymbol{x}}_{k \mid k-1}=\boldsymbol{F}_{k-1}\left(\hat{\boldsymbol{x}}_{k-1}\right)$.

When a new measurement vector $\boldsymbol{z}_{k}$ at time $k$ becomes available, an update to the predicted estimate $\hat{\boldsymbol{x}}_{k \mid k-1}$ that includes the extra information is possible. This allows the updating stage by observing, first of all, how mean values of $\boldsymbol{z}_{k}$ propagate through time. Using Equation (8b), the predicted process output $\hat{\boldsymbol{y}}_{k \mid k-1}$ becomes (given that $\boldsymbol{\nu}_{k}$ is white noise with zero mean),

$\hat{\boldsymbol{y}}_{k \mid k-1}=\boldsymbol{H} \hat{\boldsymbol{x}}_{k \mid k-1}$.

The difference between the observed measurements $\boldsymbol{z}_{k}$ and the predicted output $\hat{\boldsymbol{y}}_{k \mid k+1}$ provides a measure for the predictor stage error, also called measurement residual

$\boldsymbol{\varepsilon}_{k}=\boldsymbol{z}_{k}-\hat{\boldsymbol{y}}_{k \mid k-1}$,

\footnotetext{
${ }^{5} \mathrm{By}$ best estimator it is meant that it is the minimum mean square error estimator.
}

which should be made as small as possible.

It can be shown that the updated estimate $\hat{\boldsymbol{x}}_{k}$ that uses information up to time $k$ (note that the notation $\hat{\boldsymbol{x}}_{k \mid k}$ could have been used instead of $\hat{\boldsymbol{x}}_{k}$ ) is given by (Chui and Chen, 2009),

$\hat{\boldsymbol{x}}_{k}=\hat{\boldsymbol{x}}_{k \mid k-1}+\boldsymbol{K}_{k} \boldsymbol{\varepsilon}_{k}$,

with $\boldsymbol{K}_{k}$ known as the Kalman gain.

Figure 1 presents a block diagram describing the generic implementation of a Kalman Filter acting as a state observer. The state observer receives sampled data $z_{k}$ and outputs state estimates $\hat{\boldsymbol{x}}_{k}$ and $\hat{\boldsymbol{x}}_{k \mid k-1}$.

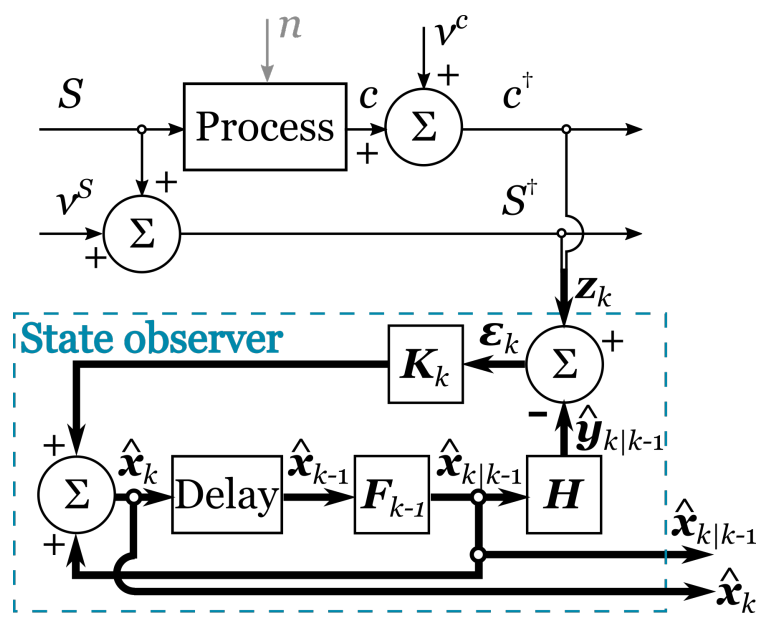

Fig. 1: Block diagram describing a Kalman Filter acting as a state observer.

As regards the Kalman gain, it is given by,

$\boldsymbol{K}_{k}=\boldsymbol{P}_{k \mid k-1} \boldsymbol{H}^{T} \boldsymbol{S}_{k}^{-1}$,

with $S_{k}$ the measurement residual covariance, obtained from

$\boldsymbol{S}_{k}=E\left(\boldsymbol{\varepsilon}_{k} \cdot \boldsymbol{\varepsilon}_{k}^{T}\right)=\boldsymbol{H} \boldsymbol{P}_{k \mid k-1} \boldsymbol{H}^{T}+\boldsymbol{V}$.

In equations (13) and (14)

$\boldsymbol{P}_{k \mid k-1}=E\left(\tilde{\boldsymbol{x}}_{k \mid k-1} \cdot \tilde{\boldsymbol{x}}_{k \mid k-1}^{T}\right)$

is the covariance for the expected error on the state prediction, called error covariance prediction, with 
$\tilde{\boldsymbol{x}}_{k \mid k-1}=\boldsymbol{x}_{k}-\hat{\boldsymbol{x}}_{k \mid k-1}$

the state prediction error.

In deriving an expression for $\boldsymbol{P}_{k \mid k-1}$, the Extended Kalman Filter makes use of a linear Taylor approximation for $\boldsymbol{x}_{k}$ at the last updated state estimate $\hat{\boldsymbol{x}}_{k-1}$ (recall that the equation for $c_{k+1}$ in (5a) is nonlinear). Defining the state $e s$ timate error as $\tilde{\boldsymbol{x}}_{k}=\boldsymbol{x}_{k}-\hat{\boldsymbol{x}}_{k}$ and with

$$
\boldsymbol{A}_{k}=\left.\frac{d \boldsymbol{F}_{k}}{d \boldsymbol{x}_{k}}\right|_{\hat{\boldsymbol{x}}_{k}}
$$

the gradient of $\boldsymbol{F}_{k}$ at $\hat{\boldsymbol{x}}_{k}$, the linearised expression for $\boldsymbol{x}_{k}$ becomes,

$\boldsymbol{x}_{k} \approx \boldsymbol{F}_{k-1}\left(\hat{\boldsymbol{x}}_{k-1}\right)+\boldsymbol{A}_{k-1} \tilde{\boldsymbol{x}}_{k-1}+\boldsymbol{r}_{k-1}$.

Replacing equations (17) and (9) into (16) makes $\tilde{\boldsymbol{x}}_{k \mid k-1}=\boldsymbol{A}_{k-1} \tilde{\boldsymbol{x}}_{k-1}+\boldsymbol{r}_{k-1}$, and using this expression in Equation (15) gives

$\boldsymbol{P}_{k \mid k-1}=\boldsymbol{A}_{k-1} \boldsymbol{P}_{k-1} \boldsymbol{A}_{k-1}^{T}+\boldsymbol{R}$,

with $\boldsymbol{P}_{k-1}=E\left(\tilde{\boldsymbol{x}}_{k-1} \cdot \tilde{\boldsymbol{x}}_{k-1}\right)$ the covariance for the expected errors on the state estimate, called updated error covariance.

Using equations (10) through (12) and equation (18), the following expression for $\boldsymbol{P}_{k}$ is derived,

$\boldsymbol{P}_{k}=\left(\boldsymbol{I}-\boldsymbol{K}_{k} \boldsymbol{H}\right) \boldsymbol{P}_{k \mid k-1}\left(\boldsymbol{I}-\boldsymbol{K}_{k} \boldsymbol{H}\right)^{T}+\boldsymbol{K}_{k} \boldsymbol{V} \boldsymbol{K}_{k}^{T}$,

where $I$ is the identity matrix.

With values for $\hat{\boldsymbol{x}}_{k}$ and $\boldsymbol{P}_{k}$ from equations (12) and (19), respectively, it is possible to move forward in time to a new predicted estimate $\hat{\boldsymbol{x}}_{k+1 \mid k}$ and new error covariance prediction $\boldsymbol{P}_{k+1 \mid k}$. Obviously, to start the procedure, initial estimates $\hat{\boldsymbol{x}}_{0}$ and $\boldsymbol{P}_{0}$ are needed; variance-covariance matrices $\boldsymbol{R}$ and $\boldsymbol{V}$ are also required.

Having developed the fundamentals of the state observer, the Matlab tool (Matlab, 2015) was used in the numerical implementation. Because the observer uses real data, including truncated and inconsistent readings, the residual covariance $\boldsymbol{S}_{k}$ was set to a large value (cancelling the updating stage, since $\boldsymbol{K}_{k}$ becomes zero) in case of truncated readings (see
Kristensen and Madsen, 2003). To avoid unphysical (e.g., negative) estimates caused by inconsistencies in data, constraints were imposed to the state estimates (see Gupta and Hauser, 2007).

\section{Test}

\subsection{Description}

To evaluate the state observer a test was conceived having window airing of a "typical" classroom (25 students; 2,16 $\mathrm{m}^{2}$ per student; $3 \mathrm{~m}$ headroom) in mind. It consisted of the following steps:

i Original time series $\left\{n_{k}^{0}\right\}$ and $\left\{\bar{s}_{k}^{0}\right\}$ were generated using a pseudorandom algorithm. $N$ was made constant and equal to 25 students during lessons.

ii Using the equation for $c_{k+1}$ in (5a), a synthetic time series $\left\{c_{k}^{\dagger}\right\}$ was obtained.

iii The state observer was used to reconstruct the original target time series $\left\{n_{k}^{0}\right\}$ from synthetic values $\left\{c_{k}^{\dagger}\right\}$, values $\left\{\bar{s}_{k}\right\}$ and $N$.

Note that in (iii) a time series $\left\{\bar{s}_{k}\right\}$-not $\left\{\bar{s}_{k}^{0}\right\}$-is used. Indeed, the original time-series for average metabolic $\mathrm{CO}_{2}$ release per person was regarded as unknown; therefore, a sequence $\left\{\bar{s}_{k}\right\}$ of mean values $\bar{s}_{k}$ had to be guessed.

The blue/ dark line at the bottom of Figure 2 represents 24 hours of the pseudorandom time series $\left\{n_{k}^{0}\right\}$. According to Bartlett et al. (2004), significant variability in air change rate occur in window-aired classrooms; this is translated into the original air change rate time series $\left\{n_{k}^{0}\right\}$, that has step changes from 2.2 to $8.3 \mathrm{~h}^{-1}$, equivalent to increasing the ventilation rate per person from 4 to $15 \mathrm{l} / \mathrm{s} / \mathrm{p}$.

The blue/ dark line at the middle of Figure 2 represents 24 hours of the pseudorandom time series $\left\{\bar{s}_{k}^{0}\right\}$. Because classroom's occupancy is intermittent with recesses of variable time span, this time series presents gaps where $\bar{s}_{k}^{0}=0$. Moreover, it was assumed that the classroom was used by classes from $5^{\text {th }}$ to $12^{\text {th }}$ grade, justifying changes in $\bar{s}_{k}^{0}$ between $0.0035 \mathrm{l} / \mathrm{s} / \mathrm{p}$ (suited for $5^{\text {th }}$ to $6^{\text {th }}$ grade classes) and $0.005 \mathrm{l} / \mathrm{s} / \mathrm{p}$ (suited for $10^{\text {th }}$ to $12^{\text {th }}$ grade classes) - see Coley and Beisteiner (2002).

At the top of Figure 2, the blue/ dark line represents 24 hours of the synthetic time series ${ }^{6}\left\{C_{k}^{\dagger}\right\}$. As described in (ii) above, these values were derived using the equation for $c_{k+1}$ in (5a).

Concerning the guessed time series $\left\{\bar{s}_{k}\right\}$, it is represented by the rose/ bright line at the middle of Figure 2. It was assumed that the classroom was used primarily by classes from $7^{\text {th }}$ to $9^{\text {th }}$ grade, justifying the mean guessed value for $\bar{s}_{k}$, of $0.00425 \mathrm{l} / \mathrm{s} / \mathrm{p}$ (during lessons).

\footnotetext{
${ }^{6} \mathrm{~A}$ constant value of outdoor $\mathrm{CO}_{2}$ concentration $C_{\mathrm{ext}}=395 \mathrm{ppm}$ was used.
} 


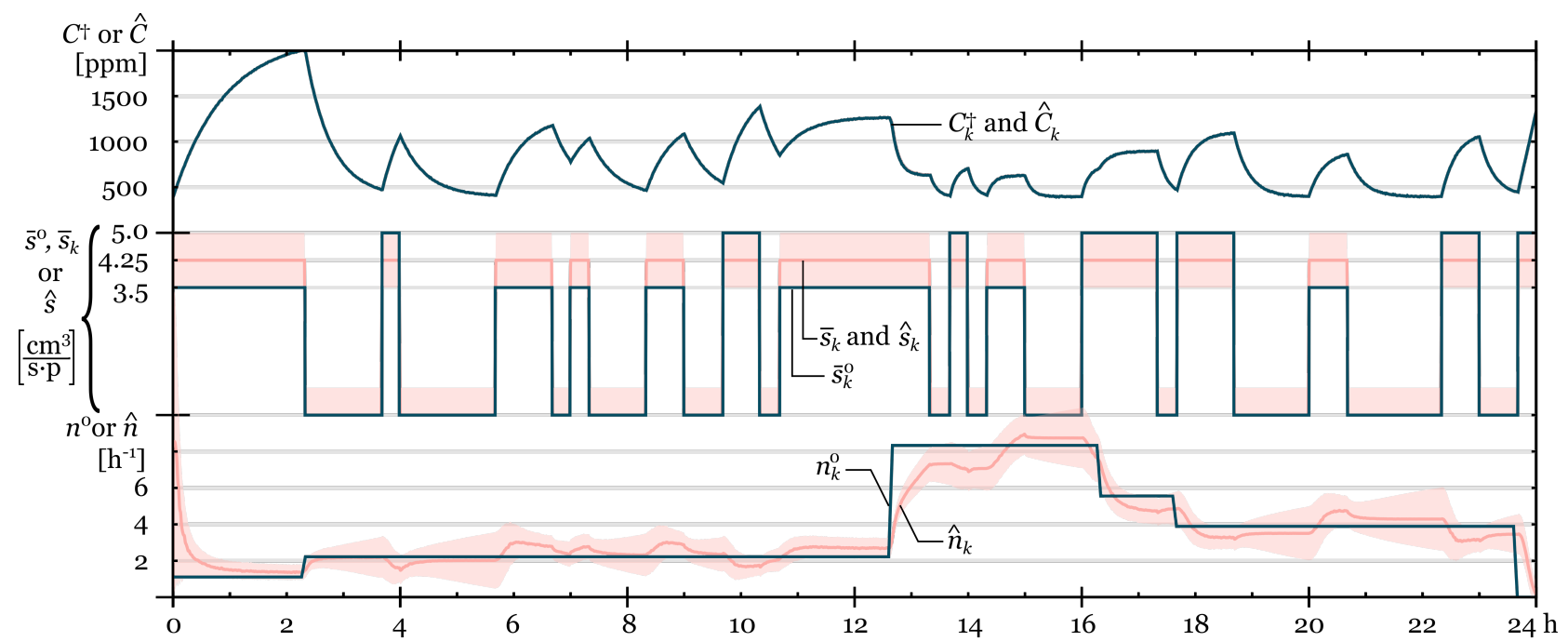

Fig. 2: Time series for original values $n_{k}^{0}$ and $s_{k}^{0}$ and synthetic values $C_{k}^{\dagger}$ generated for the test-blue/ dark lines. Estimates $\hat{n}_{k}, \hat{s}_{k}$ and $\hat{C}_{k}$ obtained with the state observer-rose/ bright lines—with respective $95 \%$ confidence intervals-rose/ bright shading areas.

As regards the variance-covariance matrices $\boldsymbol{R}$ and $\boldsymbol{V}$, all noise signals were assumed independent and covariances were set to zero. Measurement (meas) errors for indoor air $\mathrm{CO}_{2}$ concentration presumed the use of a sensor with accuracy $\pm 50 \mathrm{ppm}$, and $\left(\sigma_{\text {meas }}^{c}\right)^{2}=625 \mathrm{ppm}^{2}$ was the variance attached to $\nu_{k}^{c}$. For the error associated with the measured (actually, guessed) average rate of metabolic $\mathrm{CO}_{2}$ release per person, the variance was selected to allow 95\% confidence intervals for the estimate $\hat{s}_{k}$ encompassing the upper and lower limits 0.0035 and $0.005 \mathrm{l} / \mathrm{s} / \mathrm{p}$. This translated into a variance $\left(\sigma_{\text {meas }}^{s}\right)^{2} \approx 0.02\left(\mathrm{~cm}^{3} / \mathrm{s} / \mathrm{p}\right)^{2}$ attached to $\nu_{k}^{S}$.

The variance in process (proc) errors was not used to model any known process errors, but rather to "tell" the Extended Kalman Filter that predictions were less accurate than suggested in equation (9), and slow down the convergence of the filter. For the current test, the following variances were associated with $\left[r_{k}^{c}, r_{k}^{S}, r_{k}^{n}\right]^{T}:\left(\sigma_{\text {proc }}^{c}\right)^{2} \approx 1 \times 10^{-1} \mathrm{ppm}^{2}$, $\left(\sigma_{\text {proc }}^{\bar{s}}\right)^{2} \approx 1 \times 10^{-2}\left(\mathrm{~cm}^{3} / \mathrm{s} / \mathrm{p}\right)^{2}$ and $\left(\sigma_{\text {proc }}^{n}\right)^{2} \approx 1 \times 10^{-4} \mathrm{~h}^{-2}$.

\subsection{Results and generic discussion}

Rose/ bright lines and rose/ bright shading areas in Figure 2 are the updated estimates and respective 95\% confidence intervals-approximately $\pm 2 \sigma_{k}$-obtained with the state observer.

As expected, updated estimates $\hat{C}_{k}$ match synthetic values $C_{k}^{\dagger}$; and the scale used in Figure 2 makes it impossible to distinguish between both and distinguish the limits of the $95 \%$ confidence interval. This is of course a consequence of the small measurement noise present in $C^{\dagger}$.

As regards the updated estimates $\hat{s}_{k}$, Figure 2 confirms these are indeed equal to $0.004251 / \mathrm{s} / \mathrm{p}$ —-the guessed average rate of metabolic $\mathrm{CO}_{2}$ release per person-when the classroom is occupied and zero otherwise. As expected, for this variable a large $95 \%$ confidence interval is visible, encompassing the values 0.0035 and $0.005 \mathrm{l} / \mathrm{s} / \mathrm{p}$ used in the original time series.

Finally, concerning the unobserved ventilation rates, Figure 2 shows the state observer delivers a fair approximation to the original time series used in the test. Despite a slight lag when ventilation rate incurs sudden changes, the general tendency in the original time series is correctly captured and, considering the $95 \%$ confidence interval, it is concluded that the state observer can actually reconstruct air change rates in the classroom.

A closer look shows that a better fit to the original ventilation rates is achieved during lesson breaks, when $\bar{s}_{k}^{0}$ (and $N_{k}$ ) is zero. Moreover, when guessed values $\bar{s}_{k}$ used in the updating stage are smaller/ larger than the "true" original ones, $\bar{s}_{k}^{0}$, estimates $\hat{n}_{k}$ are also smaller/ larger than the target original values $n_{k}^{0}$.

To understand the difficulty in estimating $\hat{n}$ with uncertain $\mathrm{CO}_{2}$ releases, the way $n$ and $S(=\bar{s} \cdot N)$ are related with $c$ is studied in more detail.

\subsection{Difficulty estimating ventilation rates}

Considering constant values $n^{0}=1$ and $S^{0}=1$, a synthetic time series $\left\{c_{k}^{\dagger}\right\}$ was obtained from the difference equation for $c_{k+1}$ in Equation (5a). Then, using this same equation, different exploratory time series $\left\{c_{k}^{(n, S)}\right\}$ with $n=$ $0.5,1,1.5,2, \ldots$ and $S=0.5,1,1.5,2, \ldots$ were also determined, and the objective function given by the root mean square (RMS) of residues $\left\{\varepsilon_{k}^{(n, S)}\right\}=\left\{c_{k}^{\dagger}-c_{k}^{(n, S)}\right\}$ was rep- 
resented graphically-see Figure 3. If $S$ is known, for example, if $S=1$, the objective function is the line over the surface with $S=1$ and a clear global minimum is visible for $n=1$. In this case, the Extended Kalman Filter (or any other optimization algorithm) should be able to estimate the original target air change rate $n^{0}$. Applying this reasoning for $S=0$ helps understand why in Figure 2 a better fit to original values $n_{k}^{0}$ is achieved during lesson breaks, when $S=0$. But when both $n$ and $S$ are unknown, the objective function is the surface represented in Figure 3 and several local minima are visible.

Indeed, a global minimum for $\operatorname{RMS}\left(\left\{\epsilon_{k}^{(n, S)}\right\}\right)$ is identified when $n=1$ and $S=1$; but ordered pairs that verify the relation $n \approx S$ have values of RMS not much different from this minimum. This analysis helps understand why for "in-use" conditions and uncertainty in records of occupancy, Kalman filtering has such difficulty estimating air change rates. Returning to Figure 2, it is now clear the optimisation algorithm is estimating smaller/ larger ventilation rates than the original $\left(n_{k}^{0}\right)$ because local minima of the objective function are being found with ordered pairs $\left(\hat{n}_{k}, \hat{s}_{k}\right)$ that verify an expression of the type $\hat{n}_{k} \approx \hat{s}_{k}$. If the value $\bar{s}_{k}$ used in the updating stage is smaller than the true $\bar{s}_{k}^{0}$ then estimates $\hat{n}_{k}$ are also smaller than $n_{k}^{0}$, and vice-versa.

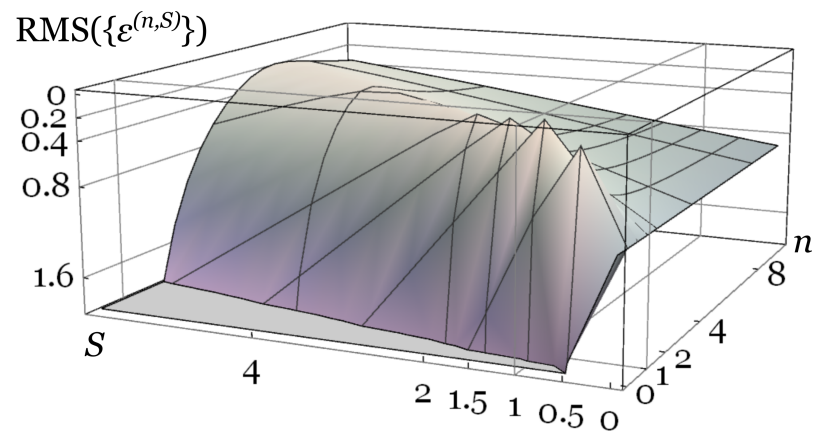

Fig. 3: Objective function $\operatorname{RMS}\left(\left\{\epsilon_{k}^{(n, S)}\right\}\right)$ showing several local minima.

This analysis applies to any optimisation algorithm and it is obvious that the noisier the measurement signals are the harder will it be to find a global minimum.

But results in Figure 2 show that despite inaccuracies, original ventilation rates $n_{k}^{0}$ fall inside the $95 \%$ confidence interval for estimates $\hat{n}_{k}$. Indeed, this test shows this occurs if the variance associated with $\nu_{k}^{S}$ is such that the $95 \%$ confidence interval for the estimates $\hat{s}_{k}$ include the original values $\bar{s}_{k}^{0}$ used to generate the synthetic time series $\left\{c_{k}^{\dagger}\right\}$.

Accepting the solution to the problem of finding ventilation rates (in the presence of uncertain occupancy measurements) is expressed as a confidence interval-not as a deterministic solution-, this test shows that knowledge of the range of plausible variance in $S$ should allow the definition of a confidence interval where the actual ventilation rates lay.
The core difficulty is then selecting the adequate mean value and associated variance of values $\bar{s}_{k}$.

With this interesting result in mind, the next section presents a case study dealing with window airing of an existing classroom. Generic conditions in the existing classroom are identical to those assumed in the test just presented, therefore, most of the options here discussed (e.g., values of $\bar{s}_{k}$ for occupied periods; matrices $\boldsymbol{R}$ and $\boldsymbol{V}$ ) apply also to the case study.

\section{Application}

\subsection{Case study description}

To test the state observer with real data and to emphasise the importance of knowing ventilation rates in window-aired rooms, a classroom of a secondary school located in Lisbon, Portugal, was selected and monitored.

Figure 4 presents a photograph of the studied classroom.

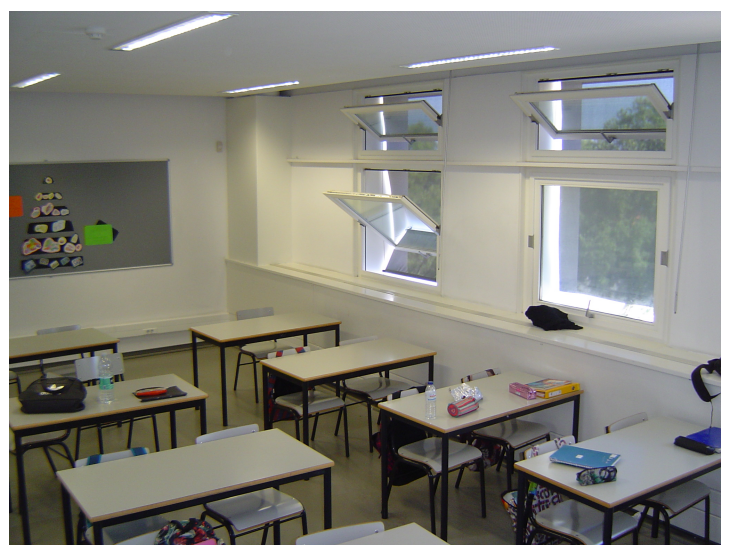

Fig. 4: Photograph of the studied classroom.

The classroom was designed for 25 students, is south oriented and has $162(9 \times 6 \times 3) \mathrm{m}^{3}$. On the south façade are three large exterior windows divided in upper and lower pivoting parts. These windows are opened manually by students, teachers and janitors. Opposite to the façade is an interior wall where the classroom door and a ventilation opening are located. As described in Duarte et al. (2017), during lessons, the ventilation in the classroom is typically single-sided (with window opening).

The classroom has air temperature and $\mathrm{CO}_{2}$ concentration sensors placed at the classroom's interior wall, approximately $2.5 \mathrm{~m}$ above the floor, away from stagnant areas and out of reach of students. Sensors characteristics are: air temperature range from -20 to $60^{\circ} \mathrm{C}$ with $\pm 0.4^{\circ} \mathrm{C}$ accuracy and $\mathrm{CO}_{2}$ concentration range from 0 to $2000 \mathrm{ppm}$ with $\pm 50 \mathrm{ppm}$ accuracy (Sauter, s/d).

Records for one week of June 2013 with warm weather were used in the study. During this period of time, along 


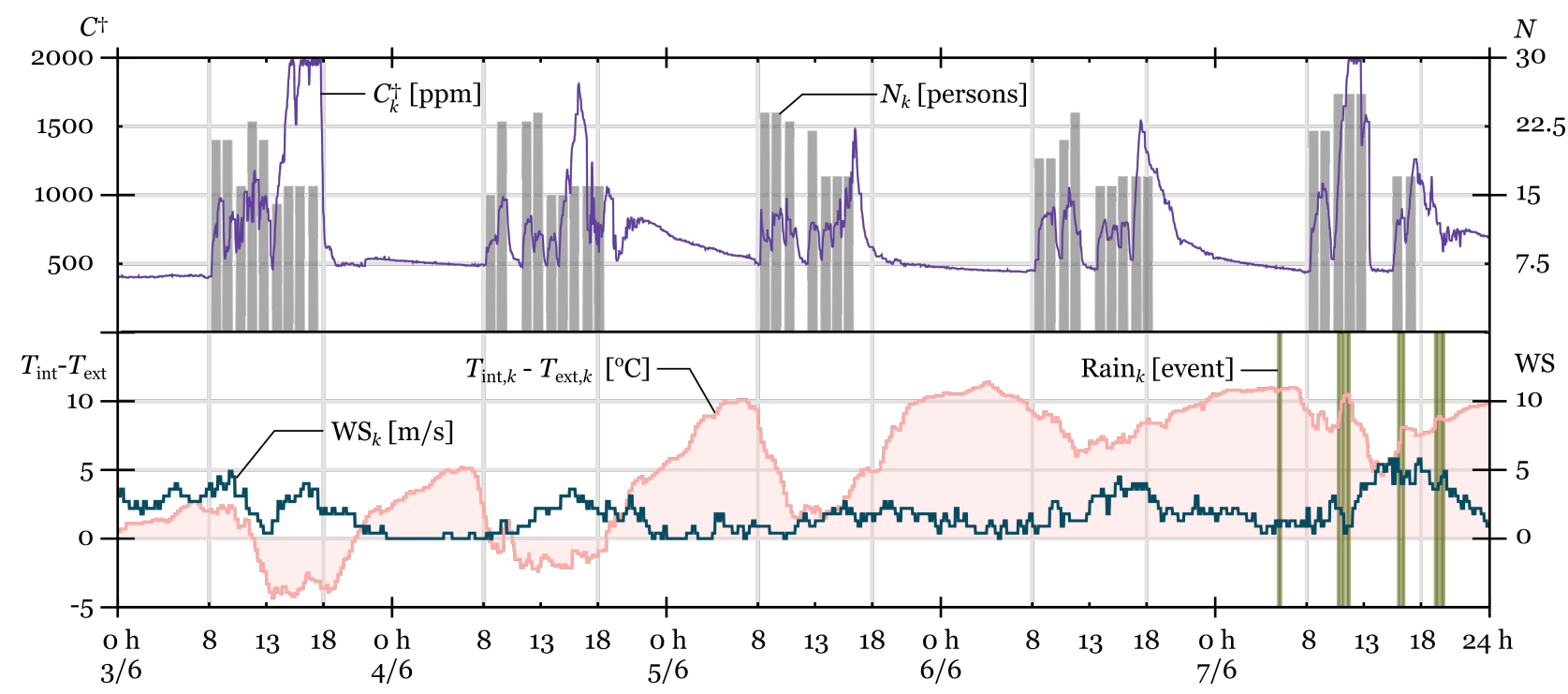

Fig. 5: Time series of indoor variables $N_{k}$ and $C_{k}^{\dagger}$ (at the top) and also of outdoor environmental variables (at the bottom), namely, measured temperature difference $\Delta T_{k}=\bar{T}_{\text {int, } \mathrm{k}}-\bar{T}_{\text {ext,k}}$, wind speed, $\mathrm{WS}_{k}$, and rain events,s $\operatorname{Rain}_{k}$.

with indoor air temperature and $\mathrm{CO}_{2}$ concentrations, lesson logs were consulted to collect the number of students and class grade (between 5th and 12th grades) that attended each lesson taught in the classroom. Outdoor conditions were also monitored using a weather station to measure air dry-bulb temperature, air relative humidity, global radiation on a horizontal plane, precipitation and wind speed. Details on range and accuracy of the weather station sensors are found in Davis (2010). Additionally, an average outdoor (atmospheric) $\mathrm{CO}_{2}$ concentration was determined $-C_{\mathrm{ext}}=$ $395 \mathrm{ppm}$ - using a sensor with characteristics described in CO2Meter (2011).

A more comprehensive explanation of the monitoring campaign is presented in Duarte et al. (2017).

Figure 5 depicts the data used in the study. The top part of this figure shows time series of indoor air $\mathrm{CO}_{2}$ concentration and number of students per lesson taught. The bottom part of Figure 5 presents times series for indoor-outdoor temperature difference, wind speed and also rain events.

Figure 5 shows the effect occupancy has on indoor air $\mathrm{CO}_{2}$ concentrations, with concentrations rising during occupied periods, in some cases above $2000 \mathrm{ppm}$. However, Figure 5 also makes it clear that besides occupancy, other factors determine changes in indoor air $\mathrm{CO}_{2}$ concentration; indeed, for the studied week with warm weather (mean, minimum and maximum indoor air temperatures of $24.5,22.1$ and $25.7^{\circ} \mathrm{C}$, respectively), the largest increases in $\mathrm{CO}_{2}$ concentrations appear to be related to larger outdoor air temperatures (negative values $\Delta T_{k}=\bar{T}_{\mathrm{int}, \mathrm{k}}-\bar{T}_{\mathrm{ext}, \mathrm{k}}$ ) and larger wind speeds or, to rain events.

Figure 5 shows two additional features of time series for measured indoor air $\mathrm{CO}_{2}$ concentrations. Readings are trun- cated at $2000 \mathrm{ppm}$ (this is caused by the sensor's upper range limit) and readings appear incongruent with occupancy data. This latter situation is easily detected on June 4 after 18 PM, with an increase in $\mathrm{CO}_{2}$ concentration with no corresponding increase in occupancy. In reality, the classroom was used to teach evening classes, but since the analysis focused on daytime activities, logs of evening classes were not consulted. Such incongruences may also occur at the start and at the end of daytime lessons because, for brief instants, records on number of students may lag (or lead) actual occupancy resulting in unphysical air change rate estimates. The problems caused by truncated readings and unphysical estimates were addressed with the methods briefly described at the end of Section 2.4.

\subsection{Estimates of ventilation rate}

With the state observer described in Section 2 and taking values for $\bar{s}_{k}$ (during lessons), $\boldsymbol{R}$ and $\boldsymbol{V}$ as in the test of Section 3.1, records of indoor air $\mathrm{CO}_{2}$ concentration and occupancy (vector $\boldsymbol{z}_{k}$ ) were used to obtain predicted and updated state estimates $\hat{\boldsymbol{x}}_{k \mid k-1}$ and $\hat{\boldsymbol{x}}_{k}$, as well as respective variances, obtained from $\boldsymbol{P}_{k \mid k-1}$ and $\boldsymbol{P}_{k}$.

Figure 6 presents time series of updated state estimates $\hat{\boldsymbol{x}}_{k}$-rose/ bright lines-and their $95 \%$ confidence intervals (approximately $\pm 2 \sigma_{k}$ )—rose/ bright shading areas. The time series for measured indoor air $\mathrm{CO}_{2}$ concentrations $\left\{C_{k}^{\dagger}\right\}$ and for guessed values $\{\bar{s}\}$ are also presented—see the blue/ dark lines.

As expected, the agreement between estimates $\hat{C}_{k}$ and measurements $C_{k}^{\dagger}$ is very good, except when measured values are truncated at $2000 \mathrm{ppm}$. In this latter case, as mentioned in Section 2.4, values $\boldsymbol{S}_{k}$ are set to a large value 


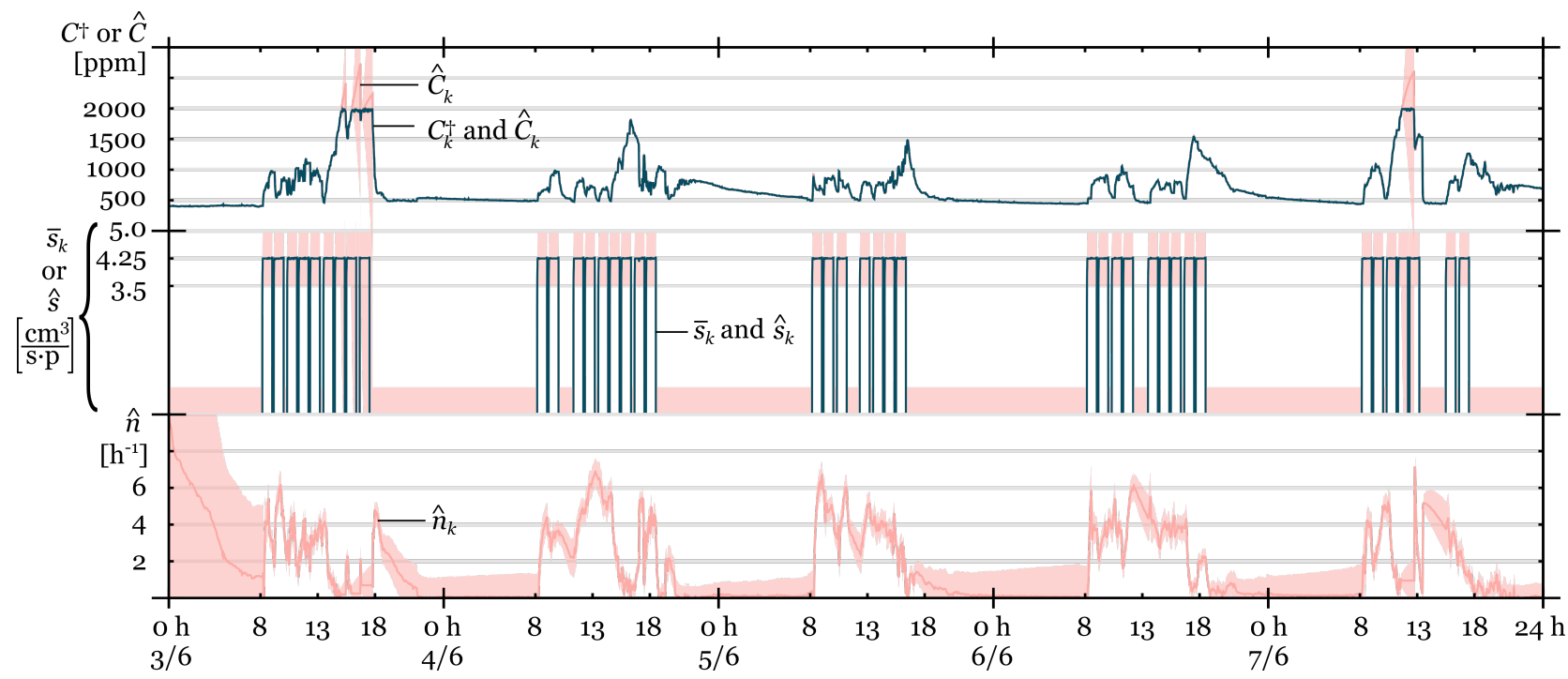

Fig. 6: Time-series of updated estimates for $\hat{C}_{k}, \hat{s}_{k}$ and $\hat{n}_{k}$-rose/ bright lines-, with their respective 95\% confidence intervals—rose/ bright shading area. Measured values of $C_{k}^{\dagger}$ and guessed values $\bar{s}_{k}$ are also represented—blue/ dark lines—and coincide with the estimates (for $C_{k}^{\dagger}$, only if lower than $2000 \mathrm{ppm}$ ).

( $\boldsymbol{K}_{k}$ becomes zero), preventing the updating stage. Naturally, without updating, the uncertainty in estimates has to increase and, indeed, this is visible in Figure 6 with large 95\% confidence intervals associated with estimates $\hat{C}_{k}$ exceeding 2000 ppm.

As regards the average rate of metabolic $\mathrm{CO}_{2}$ production per person, estimates $\hat{s}_{k}$ reproduce the guessed mean value $\bar{s}_{k}=0.00425 \mathrm{l} / \mathrm{s} / \mathrm{p}$ (during lessons), with $95 \%$ confidence interval ranging from 0.0035 to $0.005 \mathrm{l} / \mathrm{s} / \mathrm{p}$, values appropriate for classes from $5^{\text {th }}$ to $12^{\text {th }}$ grade.

Finally, for the updated estimates of air change rate $\hat{n}_{k}$, because this is an unobserved state, it is not possible to assess the accuracy of the estimates; nevertheless, judging from the results drawn for the test, in Section 3.3, actual air change rates should be bounded by the upper and lower $95 \%$ confidence interval limits for $\hat{n}_{k}$. Figure 6-bottom part-shows that during lessons these limits are not much different from the estimate $\hat{n}_{k}$ and, judging from measurements of indoor air $\mathrm{CO}_{2}$ concentrations, air change rates indeed appear to make sense, with larger concentrations coinciding with lower air change rates and vice-versa.

Further evidence that estimates $\hat{n}_{k}$ do make sense is provided in Figure 7. This figure presents measurements of indoor air $\mathrm{CO}_{2}$ concentration $C_{k}^{\dagger}$ and $95 \%$ confidence interval of estimates for ventilation rate per person. These estimates are obtained during lessons from,

$\hat{q}_{k}=\frac{\hat{n}_{k} V}{N_{k}}$.

Considering the colour coding described in Table 1, it is possible to use Figure 7 to compare levels of expectation of the environment inside the classroom, from two different but related perspectives: $\mathrm{CO}_{2}$ concentration and ventilation rate.

Indeed, according to EN ISO 15251 (2007), and considering stationary conditions, a link between values of $C_{k}^{\dagger}$ and $\hat{q}_{k}$ is possible for the four categories or "levels of expectation" described in Table 1.

Table 1: Levels of expectation and associated ranges of ventilation rate per person and indoor air $\mathrm{CO}_{2}$ concentration (EN ISO 15251, 2007).

\begin{tabular}{cccc}
\hline $\begin{array}{c}\text { Level of } \\
\text { expectation }\end{array}$ & $\begin{array}{c}\boldsymbol{q} \\
{[\mathbf{l} / \mathbf{s} / \mathbf{p}]}\end{array}$ & $\begin{array}{c}\boldsymbol{C}^{\dagger} \\
\text { [ppm] }\end{array}$ & $\begin{array}{c}\text { Colour in } \\
\text { Figure 7 }\end{array}$ \\
\hline I. High & $>10$ & $<750$ & Bright green \\
II. Normal & $7 \sim 10$ & $750 \sim 900$ & Dark green \\
III. Acceptable & $4 \sim 7$ & $900 \sim 1200$ & Orange \\
IV. Below level III & $<4$ & $>1200$ & Dark Red \\
\hline
\end{tabular}

Although stationary conditions are not expected when the classroom is "in-use", the colour coding should identify time periods with similar levels of expectation in both top and bottom parts for Figure 7. And indeed this match is visible in Figure 7.

\section{Discussion}

The test presented in Section 3 proved the tracking ability of the Extended Kalman Filter and proved that despite large step changes in "true" ventilation rate and significant uncertainty in guessed rates of metabolic $\mathrm{CO}_{2}$ release, the state observer was able to reconstruct the "true" ventilation from measurements of indoor $\mathrm{CO}_{2}$ concentration. 


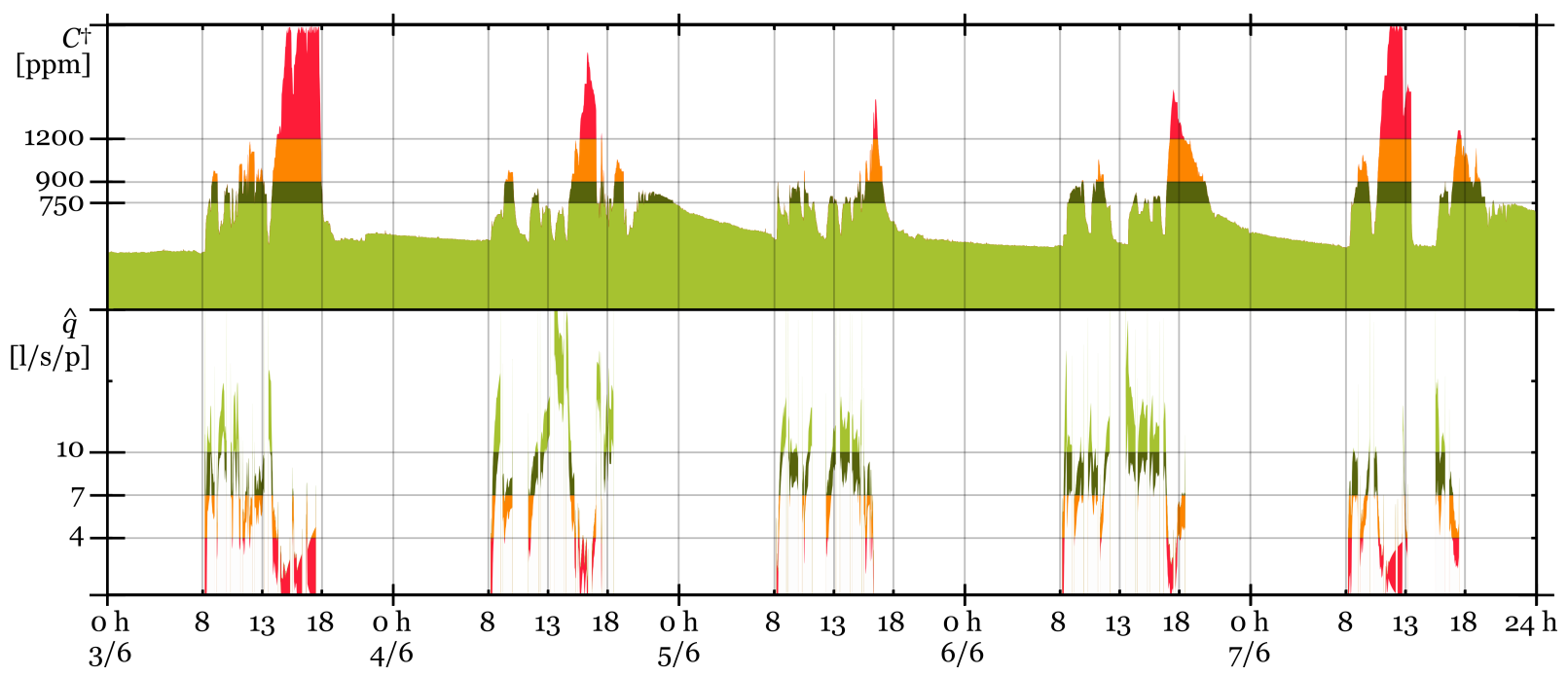

Fig. 7: Time series of measured indoor air $\mathrm{CO}_{2}$ concentration $C_{k}^{\dagger}$ (top part) and $95 \%$ confidence interval of estimates for ventilation rate per person $\hat{q}_{k}$ (bottom part). Both measured and estimated results are colour-coded according to the categories defined in EN ISO 15251 (2007)-see Table 1.

The study presented in Section 3.3 showed the critical importance of appropriate "guesses" for mean and variance values for $\mathrm{CO}_{2}$ released. Large variances associated with $\mathrm{CO}_{2}$ release lead to large uncertainty in ventilation rate estimates, but this can be a small price to pay when the number of occupants and their metabolism are known with little accuracy.

Because the setting used in the test was similar to the one for the case study, results for the test support the ability the state observer has to track and reconstruct "true" ventilation rates for the case study too. This inference is backed by the qualitative analysis allowed by Figure 7.

Figure 7 is indeed interesting in different ways and shows that the availability of data on ventilation rate could be used to change the way designers and building managers look at natural ventilation. Typically, whenever time series of indoor air $\mathrm{CO}_{2}$ concentration are presented for window-aired rooms, it is impossible not to notice the periods with concentrations higher than $\sim 1000 \mathrm{ppm}$, and to associate poor indoor air quality to window airing. This association is highlighted at the top of Figure 7 using dark red colour for concentrations above $1200 \mathrm{ppm}$. A striking feature of the time series for ventilation rate estimates, at the bottom of Figure 7, is that it highlights precisely the opposite, that is, it makes it impossible not to notice the periods with "premium" ventilation rate—bright green areas with $\hat{q}_{k}>10 \mathrm{l} / \mathrm{s}$ of fresh air per person-, associating window airing with excellent indoor air quality.

Indeed, if time series of estimates of ventilation rate and time series of associated upper and lower $95 \%$ confidence interval limits are used to obtain Figure 8, presenting cumulative distribution functions, it is concluded that insufficient ventilation $\left(\hat{q}_{k}<4 \mathrm{l} / \mathrm{s} / \mathrm{p}\right)$ was observed approximately $25 \%$ of the time. But window airing allowed acceptable ventilation rates $\left(\hat{q}_{k}>4 \mathrm{l} / \mathrm{s} / \mathrm{p}\right)$ for approximately $75 \%$ of the time the classroom was being used; moreover, approximately $25 \%$ of this time the ventilation rates exceeded $10 \mathrm{l} / \mathrm{s}$ of fresh air per person, with consequent benefit to the teaching and learning process and to students' well-being.

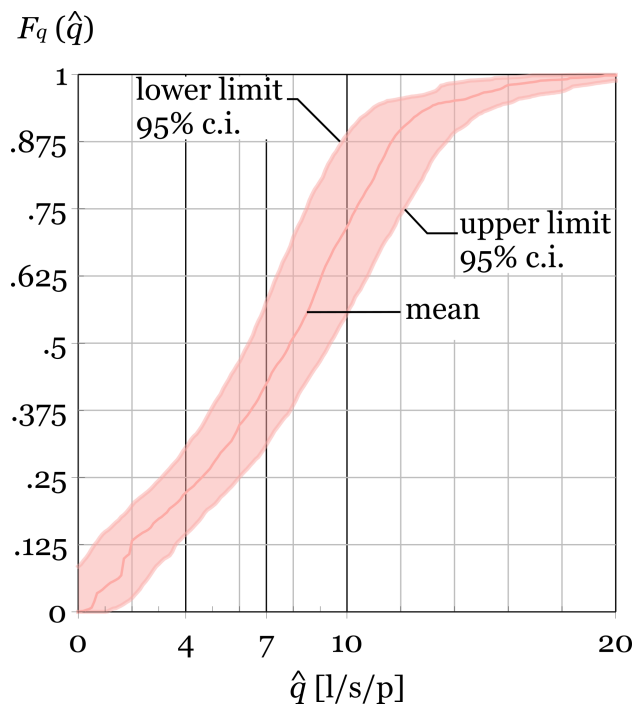

Fig. 8: Cumulative distribution function (CDF) obtained from results of mean, upper and lower limits of the $95 \%$ confidence interval (c.i.) of $\hat{q}_{k}$.

These results, the ability to express indoor conditions using the nomenclature of HVAC design, highlight the interest and importance to designers, building managers and ulti- 
mately to occupants, of knowing ventilation rates in windowaired rooms.

\subsection{Conclusions}

Although natural ventilation is one of the most frequent and impacting physical processes occurring in buildings its inherent unpredictability and reliance on occupants' behaviour makes it a remarkably complex topic. And yet, comprehending natural ventilation is of great importance to building design. This paper contributes to the understanding of natural ventilation by proposing the "quasi-instantaneous" estimation of ventilation rates using Kalman filtering and considering uncertain measurements of occupancy $\left(\mathrm{CO}_{2}\right.$ release) and $\mathrm{CO}_{2}$ concentration. The fundamental equations were derived, successfully tested on a problem with known solution and applied to an existing window-aired classroom.

Test results showed:

- The Kalman filter tracking capability and its ability to reconstruct ventilation rates in the presence of sudden changes caused by window opening/ closing and intermittent occupancy;

- That the uncertainty in estimates of ventilation rate is determined by the uncertainty in occupancy $\left(\mathrm{CO}_{2}\right.$ release);

- That the solution to estimating ventilation rates with uncertain occupancy $\left(\mathrm{CO}_{2}\right.$ release $)$ is best defined in terms of confidence intervals;

- That tests like the one presented could be used to assess if confidence intervals for estimates of ventilation rate include the "true" ventilation rate.

Results for the existing classroom showed:

- That the ability to express indoor conditions in terms of ventilation rate-i.e., using the nomenclature of HVAC design - is important to ventilation design and air quality auditing in window-aired rooms;

- That window-airing allowed acceptable ventilation rates during most of the school day and allowed premium ventilation rates (above $10 \mathrm{l} / \mathrm{s}$ of fresh air per student) $25 \%$ of the time.

The promising results obtained in this paper support Kalman filtering could be used to further investigate natural ventilation in buildings.

\section{References}

Almeida, R. and Freitas, V.: Indoor environmental quality of classrooms in Southern European climate, Energy and Buildings, 81, 127-140, 2014.

ASTM D6245-98: Standard guide for using indoor carbon dioxide concentrations to evaluate indoor air quality and ventilation, ASTM International, United States of America, 2002.
ASTM E741-00: Standard test method for determining air change in a single zone by means of a tracer gas dilution, ASTM International, United States of America, 2006.

Bakó-Biró, Z., Clements-Croome, D., Kochhar, N., Awbi, H., and Williams, M.: Ventilation rates in schools and pupils' performance, Building and Environment, 48, 215-223, 2012.

Bartlett, K., Martinez, M., and Bert, J.: Modelling of occupantgenerated $\mathrm{CO}_{2}$ dynamics in naturally ventilated classrooms, Journal of Occupational and Environmental Hygiene, 1, 139148, 2004.

Brabec, M. and Jílek, K.: State-space dynamic model for estimation of radon entry rate, based on Kalman filtering, Journal of Environmental Radioactivity, 98, 285-297, 2007.

Chui, C. and Chen, G.: Kalman filtering with real-time applications, Springer, $4^{\text {th }}$ edn., 2009.

CO2Meter: $\mathrm{CO}_{2} 1 \%$ or $30 \%$, Temperature \& \% RH, Diffusion Data Loggers, www.co2meter.com (accessed May 2015), 2011.

Coley, D. and Beisteiner, A.: Carbon Dioxide levels and ventilation rates in schools, International Journal of Ventilation, 1, 45-52, 2002.

Davis: Precision Weather Instruments, Davies Instruments 2010 Catalog, 2010.

D'Souza, A.: Design of control systems, Prentice-Hall, Inc., 1988.

Duarte, R., Glória Gomes, M., and Moret Rodrigues, A.: Classroom ventilation with manual opening of windows: Findings from a two-year-long experimental study of a Portuguese secondary school, Building and Environment, 124, 118-129, 2017.

EN ISO 12569: Thermal performance of building-determination of air change rate in buildings - tracer gas dilution method, CENEuropean Committee for Standardization: Brussels, Belgium, 2000.

EN ISO 15251: Indoor environmental input parameters for design and assessment of energy performance of buildings addressing indoor air quality, thermal environment, lighting and acoustics, CEN-European Committee for Standardization: Brussels, Belgium, 2007.

Fraga, S., Ramos, E., Martins, A., Samúdio, M., Silva, G., Guedes, J., Oliveira-Fernandes, E., and Barros, H.: Indoor air quality and respiratory symptoms in Porto schools, Revista Portuguesa de Pneumologia, XIV, 487, 2008.

Geelen, L., Huijbregts, M., Ragas, A., Bretveld, R., Jans, H., Doorn, W., Evertz, S., and Zjiden, A.: Comparing the effectiveness of interventions to improve ventilation behaviour in primary schools, Indoor Air, 18, 416-424, 2008.

Griffiths, M. and Eftekhari, M.: Control of $\mathrm{CO}_{2}$ in a naturally ventilated classroom, Energy and Buildings, 40, 556-560, 2008.

Gupta, N. and Hauser, R.: Kalman filtering with equality and inequality state constraints, Report 07/18, Oxford University Computing Laboratory, Numerical Analysis Group, 2007.

Jimenéz, M. and Madsen, H.: Models for describing the thermal characteristics of building components, Building and Environment, 43, 152-162, 2008.

Jones, W.: Air Conditioning Engineering, Edward Arnold, $4^{\text {th }}$ edn., 1994.

Kristensen, N. and Madsen, H.: Continuous Time Stochastic Modelling, CTSM 2.3-Mathematics Guide, Tech. rep., Technical University of Denmark, 2003.

Ljung, L.: System Identification: Theory for the User, Prentice Hall, 1987. 
Madsen, H. and Holst, J.: Estimation of continuous-time models for the heat dynamics of a building, Energy and Buildings, 22, 6779, 1995.

Markov, D. and Melikov, A.: Novel approach for evaluation of air change rate in naturally ventilated occupied spaces based on metabolic $\mathrm{CO}_{2}$ time variation, in: Proceedings of Indoor Air 2014, July 7-12, Hong Kong, Paper HP0883, 2014.

Matlab: MATLAB version 8.5 (R2015a), The Mathworks, Inc., Natick, Massachusetts, 2015.

Mendell, M. and Heath, G.: Do indoor pollutants and thermal conditions in schools influence student performance? A critical review of the literature, Indoor Air, 15, 27-52, 2005.

Okuyama, H.: System identification theory of the thermal network model and an application for multi-chamber airflow measurement, Building and Environment, 25, 349-363, 1990.

Okuyama, H. and Onishi, Y.: Uncertainty analysis and optimum concentration decay term for air exchange rate measurements: Estimation methods for effective volume and infiltration rate, Building and Environment, 49, 182-192, 2012.

Pegas, P., Alves, C., Evtyugina, M., Nunes, T., Cerqueira, M., Franchi, M., Pio, C., Almeida, S., Cabo Verde, S., and Freitas, M.: Seasonal evaluation of outdoor/indoor air quality in primary schools in Lisbon, Journal of Environmental Monitoring, 13, 657-667, 2011.

Penman, L.: An experimental determination of ventilation rate in occupied rooms using atmospheric carbon dioxide concentration, Building and Environment, 15, 45-47, 1980.

Penman, L. and Rashid, A.: Experimental determination of air-flow in a naturally ventilated room using metabolic carbon dioxide, Building and Environment, 17, 253-256, 1982.

Pereira, L., Raimondo, D., Corgnati, S., and Gameiro-da Silva, M.: Assessment of indoor air quality and thermal comfort in Portuguese secondary classrooms: Methodology and results, Building and Environment, 81, 69-80, 2014.

Petersen, S., Jensen, K., Pedersen, A., and Rasmussen, H.: The effect of increased classroom ventilation rate indicated by reduced $\mathrm{CO}_{2}$ concentration on the performance of schoolwork by children, Indoor Air, 2015.

Reid, G.: Linear system fundamentals: Continuous and discrete, classic and modern, McGraw-Hill, 1983.

Rudnick, S. and Milton, D.: Risk of indoor airborne infection transmission estimated from carbon dioxide concentration, Indoor Air, 13, 237-245, 2003.

Santamouris, M., Synnefa, A., Asssimakopoulos, M., Livada, I., Pavlou, K., Papaglastra, M., Gaitani, N., Kolokotsa, D., and Assimakopoulos, V.: Experimental investigation of the air flow and indoor carbon dioxide concentration in classrooms with intermittent natural ventilation, Energy and Buildings, 40, 1833-1843, 2008.

Sauter: Sauter components catalog for EGQ 212, 222: Transducers for $\mathrm{CO}_{2}$ and temperature, s/d.

Sherman, M.: Tracer-gas techniques for measuring ventilation in a single zone, Building and Environment, 25, 365-374, 1990.

Smith, P.: Determination of ventilation rates in occupied buildings from metabolic $\mathrm{CO}_{2}$ concentrations and production rates, Building and Environment, 23, 95-102, 1988.

Wargocki, P. and da-Silva, N.: Use of visual $\mathrm{CO}_{2}$ feedback as a retrofit solution for improving classroom air quality, Indoor Air, $25,105-114,2015$.
Wargocki, P. and Wyon, D.: The effects of moderately raised classroom temperatures and classroom ventilation rate on the performance of schoolwork by children (RP-1257), HVAC\&R Research, 13, 193-220, 2007a.

Wargocki, P. and Wyon, D.: The effects of outdoor air supply rate and supply air filter condition in classrooms on the performance of schoolwork by children (RP-1257), HVAC\&R Research, 13, 165-191, 2007b. 